\title{
Personalizing antiplatelet therapy-moving to clinics
}

\author{
Subraja Kumaresan • Steven Dkhar
}

Received: 24 October 2012 / Accepted: 24 October 2012 /Published online: 13 November 2012

(C) Springer-Verlag Berlin Heidelberg 2012

\section{Dear Editor,}

The commentary "Bringing pharmacogenetics to the bedside," published in this issue by Gupta, focuses on the applications of genetic testing in personalizing antiplatelet therapy.

Robust evidence from various studies including genome wide studies has established the genetic influence of CYP2C19 genotypes on the outcome of clopidogrel therapy. Now researchers are attempting to take this from the bench to the bedside. As mentioned by the author in the commentary, cost is a limiting factor for implementing pharmacogenomics in practice. This cost issue was addressed in a model-based cost effectiveness analysis that evaluated the benefit of CYP2C19 genotype-guided antiplatelet therapy over the conventional therapy, irrespective of the genotype [1]. They concluded that genotype-guided antiplatelet therapy is more cost effective, with fewer adverse outcomes.

The beginning of personalized medicine in clinical practice can be evidenced from the reports of the prospective proof of concept trial, which introduced point-of-care genetic testing for initiating antiplatelet therapy [2]. This point of care genetic test was validated and gave rapid results within minutes. The test can be effectively done by nurses at the bed side.

A more pragmatic approach in the implementation of genotyping in personalized medicine was presented in the Vanderbilt PREDICT project [3]. This multidisciplinary project, with experts from various fields such as medicine, clinical pharmacology and clinical pathology, etc., was designed to incorporate genotyping of CYP2C19 for usage of clopidogrel in individuals undergoing cardiac catheterisation. The project aims at developing electronic medical records of genotyping and evidence based decision-support

\section{S. Kumaresan $(\bowtie) \cdot$ S. Dkhar}

Department of Pharmacology, Jawaharlal Institute of Postgraduate

Medical Education and Research (JIPMER),

Pondicherry, India

e-mail: subrajakumaresan84@gmail.com algorithms and rules in guiding the practitioners for prescribing. Success of this PREDICT project can further lead to incorporation of other drug gene interactions, including warfarin-CYP2C9 and simvastatin-SLCO1B1.

Further encouragement is provided by insurance services that decided to reimburse the cost expense spent towards genetic testing [4]. These firms have realised that genetic testing is a cost effective strategy for implementing efficacious drug therapy with minimal side effects.

It is reasonable to conclude that medical science has advanced to its best in making the possibility of incorporating pharmacogenomic testing to clinical practice. Hence, the new era of personalized tailored antiplatelet therapy is not very far from our reach.

Sincerely,

Subraja K MD,

Dkhar SA MD.

\section{References}

1. Reese ES, Daniel Mullins C, Beitelshees AL, Onukwugha E (2012) Cost-effectiveness of cytochrome P450 2C19 genotype screening for selection of antiplatelet therapy with clopidogrel or prasugrel. Pharmacotherapy 32:323-332

2. Roberts JD, Wells GA, Le May MR, Labinaz M, Glover C, Froeschl M, Dick A, Marquis J-F, O'Brien E, Goncalves S, Druce I, Stewart A, Gollob MH, So DYF (2012) Point-of-care genetic testing for personalisation of antiplatelet treatment (RAPID GENE): a prospective, randomised, proof-of-concept trial. Lancet 379:1705-1711

3. Pulley JM, Denny JC, Peterson JF, Bernard GR, Vnencak-Jones CL, Ramirez AH, Delaney JT, Bowton E, Brothers K, Johnson K, Crawford DC, Schildcrout J, Masys DR, Dilks HH, Wilke RA, Clayton EW, Shultz E, Laposata M, McPherson J, Jirjis JN, Roden DM (2012) Operational implementation of prospective genotyping for personalized medicine: the design of the Vanderbilt PREDICT project. Clin Pharmacol Ther 92:87-95

4. Pharmacogenetic and Pharmacodynamic Testing. Available at http:// www.aetna.com/cpb/medical/data/700_799/0715.html. Accessed 24 Oct 2012 